\title{
BEFERENGIAS BIBLIOCRARICAS
}

COMISSÃO ESPECIAL PARA ESTUDODO SISTEMA PREVIDENCIÁRIO. Previdéncia em Dados. Bio de Janeiro,

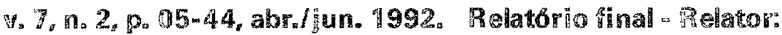
Antonio Britro

COVRE, Maria de Lourdes M. Capital monopolista: da cidadania que não temos à invenção democrâticica, In: $A$ cidadania que não temos. São Paulo: Brasilliense, 1986.

FALEIROS, Vicente de Paula A polfitica social no Estado capitalista: as funçöes da Previdêneia Assistêneigia 30 cialo São Paulo: farterte 1985.

INSTTUTO BPASILERO DEECONOMAA. PHEMA nOYA

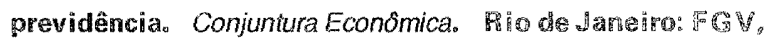
rev. 1992 p.9.12

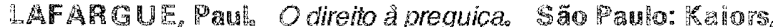
3980.

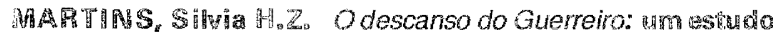

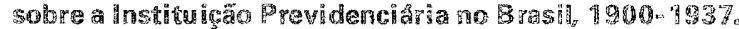

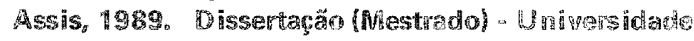
Fing

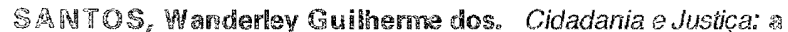

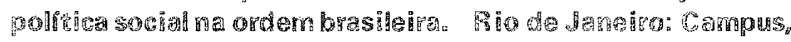
1979.

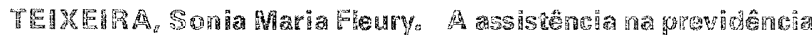

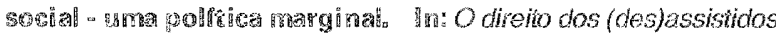

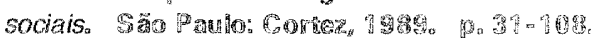

Recebido para publicaçäo em $7 / 7 / 199$

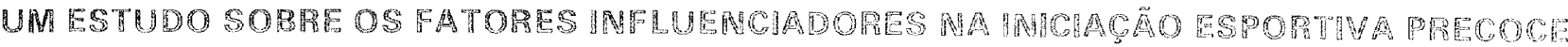

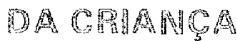

\author{
ARLIRAMOS DE OLIVEIRA?
}

OLIVEIRA, A.R. de Um estudo sobre os fatores influenciadores na iniciaçäo espontiva precoce da criança Samonthe

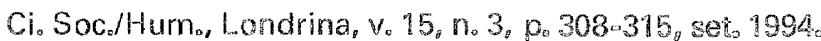

RESUMO: O presente estudo tem por objetvo analisar os possheis latores gue infuenciam na iniciaça espontha da chianca. quando realizada precocemente e sem a devida undamentacão cienuifica A salla de uma disciplina espechica vohada para o de senvolvimento inrantil, na maiona das escolas de Educaçäo fisica do Estado do paranh segundo dados da Secrobria de 5

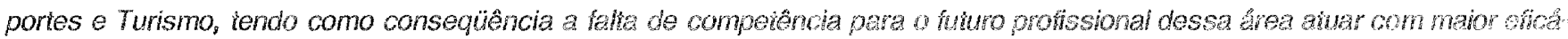

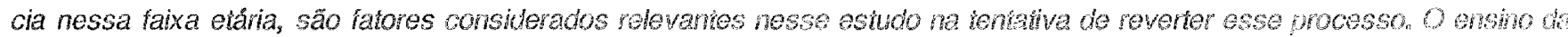

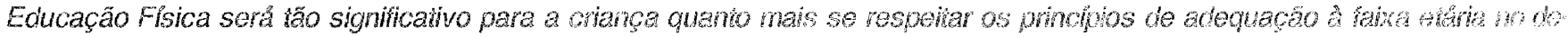

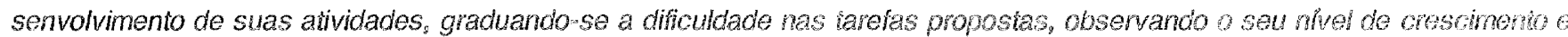
desenvolvimento, sua cratividade e espontaneidade, suas diferencas individuais, bem como suas expentencias previas no de. senvolvimento dessas aividades. A criança aprende quando esta mactura para aprender, sendo desaconselhato a bhtase na prática competitiva antes dos 12 anos de idade, e prevenindo a ocorrencia de lesóes, em runção de possiveis oxcessos. Heco. menda-se uma melhor formaça profissional, partindo da reesiruturaça curricular das Escolas de Educaça Flsicas com maior concentração na área de Crescimento e Desenvolvimento Infanîl. Torna-se imporante a adequacão dessa prática ao nivel de interesse e evolução da criança, respeitando se necessidades, interesses e possibilidades de exectuçäo, motivando a criança a adquirir gosio pelo movimento e manter o hábito da prática da aívidade fisica, com a finalidade de presenvar a sua saude.

PALAVAAS-CHAYE: Iniciação esportiva precoce; criança; fatores influentes

Todo processo educacional brasileiro encontra-se na atualidade numa grande crise. Uma crise existencial, onde a mudança se torna necessária. E o momento de decisão se faz presente, exigindo de cada profissional da educaçäo novas posturas politicas, onde um comprome- timento maior com todo esse processo se faz necessário: por parte do professor, por parte dos alunos, pelos diretores das escolas, pelas Secretarias Estaduais de Educação, pelos seus governos. É necessário mudar o ensino nas escolas do Brasil, fazendo com que a Educação Fisica

1 - Departamento de Ginåstica, Recreação e Dança/CEFD - Universidade Estadual de Londrina, Caixa Postal 6001, Londrina, Paraná, Brasil, CEP 86051-970. 
se volte para o desenvolvimento global de cada aluno.

No Paraná, segundo dados da Secretaria Estadual de Esportes e Turismo, das 10 escolas de Educação Fisica existentes, apenas 3 delas possuem em seus curriculos uma disciplina especffica voltada para a Educação Física Infantil. Isso tende a acarretar uma carência na formação profissional e no desenvolvimento científico dessa área especifica, notadamente percebida na atuação profissional e no seu desempenho. $O$ ritmo de aprendizagem individual não é respeitado, limitando a participação do aluno em sua auto-organização, auto-percepção e autoconceito. $\mathrm{Em}$ conseqüência, limita-se também a sua integração como ser independente, criativo e capaz. Continua o reforço ao autoritarismo, que forma pessoas passivas, sem opinião própria, tornando-as passiveis de qualquer forma de dominação. Percebe-se uma certa confusão entre processos de educaçăo psicomotora e iniciaçăo esportiva, por especialização esportiva. Que tipo de profissionais nossas universidades estão formando? Que perfil profissional é o mais adequado a nossa atual realidade? Será que nāo está sendo apresentado aos alunos de cursos de Educação Física um mero processo de reprodução, onde a preocupação maior continua sendo a transmissão de habilidades técnico-desportivas? Será que todo esse quadro que se apresenta não carece de uma auto-crítica mais aprofundada, ensejando tomada de posições mais fortes para que ele possa se reverter? Será que não está sendo impedida a evolução de todo esse processo, temendo o inicio de um ensino pessoal, individualizado, em aulas de Educação Física, onde o respeito às diferenças individuais e à evolução da pessoa e do homem em crescimento contínuo se fazem presentes? Diante desse quadro, tenta-se definir o papel do real educador.

\section{EDUCAÇĀO E APRENDIZAGEM}

ALVES (1985) considera que educador não é profissão, mas vocação. E toda vocação, "nasce de um grande amor, de uma grande esperança". Al talvez se encontre a grande dificuldade em criar novas alternativas. HURTADO (1987) acrescenta ainda que a um discurso que não é uma expressão de amor, "falta o poder mágico para criar". Percebe-se que a grande dificuldade na aprendizagem è a vivência que se tem sobre a experiência no aprender, pois o que é imediatamente experimentado, não precisa ser ensinado nem repetido para ser memorizado... e assimilado. $E$ muitas vezes essa falta de amor, ou de reconhecimento pelo trabalho realizado, leva 0. educador a outras atividades mais rendosas, ainda que menos significativas. A buscar pela aposentadoria, e a manter distância dessas crianças o mais rápido possivel. Mas toda vivência gratificante tende a ser repetida e, pois "que amante quereria aposentar o seu corpo depois de vinte e cinco anos de experiências de amor? $O$ amor e a paixão não anseiam pela aposentadoria, porque são eternamente jovens" (ALVES, 1985). Torna-se necessário co. nhecer esse corpo, que se manifesta pelo movimento, com todos os seus significados perante a vida.

Semina Ci. Soc./Hum., v. 15, n. 3, p. 308-315

\section{MOVIMENTO E CORPO}

Compreender a criança e o seu processo de desenvolvimento, torna-se uma necessidade premente, em especial dos que participam de seu processo de educação. A massa de informações que atinge o ser humano a cada momento é filtrada, selecionada, organizada, estruturada e mediada pela linguagem. É nesse mundo estruturado que se pode conhecer a si mesmo e se organizar o comportamento. O corpo é um produto da educação, e o corpo humano não é o organismo animal em sua imediatez biológica. $O$ animal é o seu corpo. Porém o homem tem o seu corpo. $E$ a esse corpo representado por grande complexo linguístico, se dá o nome de personalidade. $E$ essa personalidade pode ser melhorada, em especial se the for dada "permissão" e liberdade no desenvolvimento de sua própria liberdade interior, para que possa atingir uma interpretação significativa de sua própria existência. E o educador de amanhã, seja o mais humilde professor de um jardim da infância, ou o reitor de uma grande universidade, terá de saber, ao nível pessoal mais profundo, que posição assumirá perante a vida... se está a manipular robôs humanos, ou a tratar com pessoas individuais livres. Torna-se necessário repensar a cada momento o papel do educador no processo de educação.

\section{REPENSANDO A EDUCAÇĀO FÍSICA NO PROCESSO EDUCACIONAL}

HURTADO (1987) sugere um estudo mais aprofundado do movimento e suas implicações, enfim, do processo psicomotor, para conceitar a Educação Física como "conjunto de educação global, visando ao pleno desenvolvimento do aparelho locomotor, bem como ao desenvolvimento normal das grandes funções vitais e melhor relacionamento social". Parece que a educação dos movimentos, atravês de diversificadas experiências psicomotoras, tende a favorecer um bom desenvolvimento das capacidades naturais da criança. A questão é se essas experiências estão sendo adequadas ao seu comportamento psicomotor e às suas aptidões perceptivas. Questiona-se se o objetivo maior da atividade física näo seria em primeira instância de caráter biológico, visando a melhoria da aptidão física. Por outro lado, as escolas de Educação Física tem enfatizado a prática de esportes individuais e coletivos. Pergunta-se se a devida atenção é dada aos aspectos de estímulo ao movimento como forma de expressão individual, formação de háḅitos de higiene, e sociabilização. Torna-se necessário repensar se as atividades fisico-recreativas propiciadas às crianças tem tido um real significado para elas. É preciso saber se os princípios de adequação à faixa etária, à criatividade, ả graduação em dificuldade, à espontaneidade, estão sendo incorporadas pelas crianças nesse processo educativo. Como está o respeito às diferenças individuais, à liberdade de expressão, e às possibilidades de realização dessas crianças? As experiências de movimento a elas proporcionadas tem sido significativas e relevantes para o seu contínuo aprendizado? 
Diferentes fatores podem interferir nesse processo, visando a motivação da criança à prática da atividade fisica (Figura 1). Uma atividade torna-se significativa na medida em que atende os interesses da criança, respeita suas necessidades, possui objetivos especificos, e em conseqüência, pode gerar grande motivação à sua prática.

\section{O DESENVOLVIMENTO INFANTIL}

ARAÚJO (1987) observa que é através da repetição dos movimentos que a criança vai adquirindo o controle de seus gestos motores, o que representaria no sistema nervoso central, um melhor isolamento dos cabos elétricos. Quando esse isolamento ainda não existe, os atos motores saem confusos e sem objetividade. Ou seja, torna-se necessário saber se a criança tem maturidade suficiente para aprender o que está sendo ensinado. A aprendizagem motora ocorre pela repetição de movimentos corretos. Quando esse gesto é feito errôneamente, estabelece-se um vicio motor, tornando-se extremamente diffcil eliminá-lo e instituir um padrão correto de movimento. Uma vez aprendido um ato motor, ele não é mais perdido por completo, mas se ele não é praticado freqüentemente, cai sua possibilidade de acerto. Torna-se contraproducente tentar fazer a criança aprender algo para o qual ela ainda não está madura o suficiente. Isso pode levar à frustração. Mais uma vez, o papel da escola torna-se importante nesse processo. Evitar a comparação com outras crianças, bem como não valorizar demais o grande desempenho, ou aquela criança que consegue fazer um gesto técnico difícil de maneira correta. Em especial no âmbito escolar, se deveria respeitar a individualidade biológica da criança, não antecipando a época de início de sua atividade física através da competição exacerbada.

TUBINO (1979) adverte que "a seleção precoce de crianças para uma determinada atividade especializada, fugindo a uma espontaneidade natural encontrada nas faixas etárias mais baixas, e transformando-as num meio de resultados de terceiros, é incompativel com os preceitos educacionais que devem dirigir um processo de treinamento desportivo, por maiores nifveis que possam chegar esses futuros atletas". Isso sugere um cuidado maior com a ênfase na vitória a todo custo e a competição exacerbada, em função de seus nefastos efeitos.

\section{A CRIANÇA E A COMPETIÇĀO NA PRÁTICA ESPORTIVA}

Diversos estudos tendem a sugerir que a prática do esporte competitivo deva ser desestimulada em sua totalidade antes dos 12 anos de idade, em especial quando a ênfase maior é colocada no rendimento esportivo e na vitória a todo custo; pelos excessos que normalmente acarreta nas epifises ósseas, pela sobrecarga física; e

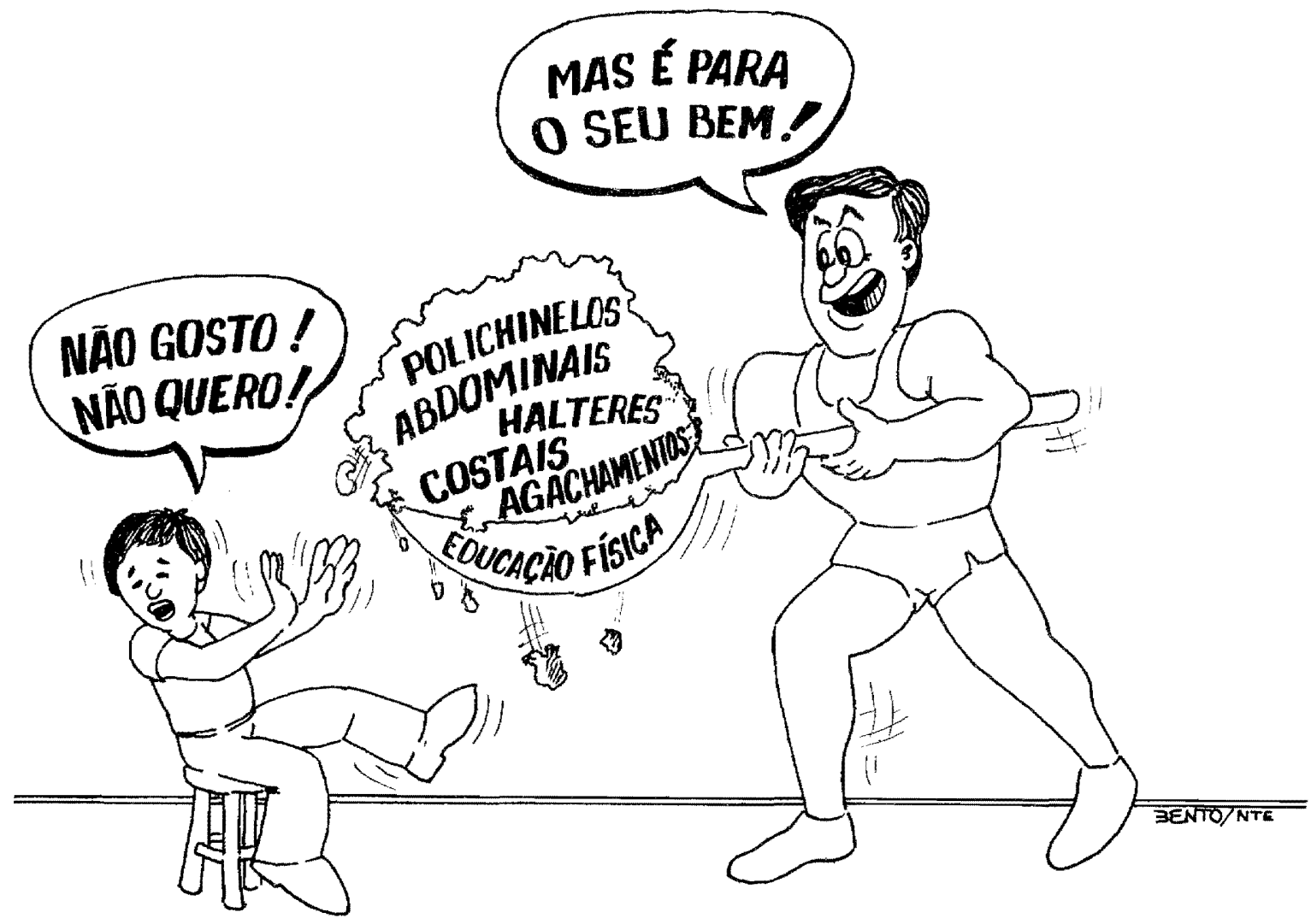

Figura 1 - ATIVIDADES SIGNIFICATIVAS E PARTICIPAÇĀO ATIVA AMPLIAM AS POSSIBILIDADES DE APRENDIZAGEM Semina Ci. Soc./Hum., v. 15, n. 3, p. 308-315 
também nas inserções musculares, podendo impedir o seu crescimento normal, por vezes de maneira irreversivel (MALINA \& BOUCHARD, 1991). Sugere-se que em especial trabalhos para o desenvolvimento da força muscular, na infância e adolescência, deveriam servir a uma formação geral harmoniosa: ser multiforme, variada, alegre, e corresponder à faixa etária que está participando da atividade. $O$ periodo crítico de aprendizagem deveria assegurar a aquisição de técnicas esportivas básicas, sob sua forma rudimentar e se possível mais elaborada, graças a uma prática racionalmente orientada. $A$ base da performance é lançada na idade escolar precoce ou tardia. No entanto, deve-se constar que todos os niveis de idade tem uma estreita relação de interdependência: os degraus posteriores se constróem sobre a base antecedente (WEINECK, 1986).

PINI (1978) aponta diferentes aspectos que deveriam ser observados quando a criança estiver envolvida na prática do esporte, em especial através de competições. Que o instinto competitivo, sendo um sentimento inato no homem, deveria ser incentivado desde a infância até a idade adulta, pela atividade física através da Educação Fisica e do Esporte. Um exame médico geral seria imprescindivel, bem como os retestes que se fazem necessários, e a constante vigilância médica durante os treinamentos. A iniciação da criança na prática esportiva obedeceria a grandes intervalos entre eles, que se vão tornando cada vez menores, à medida que o individuo vai passando da fase pré-adolescente para a puberal, e desta para a adolescência. A participação da criança nessa prática obedeceria a um verdadeiro ritual preparatório, cuja seqüência iria desde os exercicios físicos e naturais e os jogos recreativos, atê a ginástica sistematizada e précompetitiva. Sugere ainda o fisiologista, que as competições, na idade escolar, deveriam ser de caráter geral, sem visar a especialização esportiva, e se possivel restritas ao ambiente escolar. A especialização esportiva deveria ser iniciada após uma preparação física de base, realizada desde a idade pré-escolar e escolar, em especial para as modalidades esportivas que melhor se adaptam ao organismo da criança, como a natação, ginástica olímpica, e outros esportes com regras adaptadas à idade do participante.

A falta de adequação às necessidades da criança, bem como o excesso de atividades que uma criança no mundo atual possui, pode ser uma das principais fontes de stress em seu organismo (Figura 2), ainda nesse perlodo de vida.

Torna-se necessário analisar que fatores estão influenciando e contribuindo para que uma criança, na mais tenra idade, possa atingir niveis de stress antes só imaginado na pessoa adulta (HART, 1992).

\section{FATORES INFLUENCIADORES NA INICIAÇĀO ESPORTIVA PRECOCE DA CRIANÇA}

Diferentes fatores parecem estar influenciando a participação da criança na prática esportiva e competitiva. Percebe-se um certo excesso de atividades no cotidiano da criança: natação, inglês, violão, computador, ballet, Semina Ci. Soc./Hum., v. 15, n. 3, p. 308-315 volibol, basquetebol, catequese, tarefas escolares... as crianças assemelhando-se mais a mini-executivos, que só não conseguem administrar o seu dia, nem escolher suas próprias atividades. Fatores sócio-econômicos também podem criar uma certa instabilidade e incerteza no seio familiar. Também a forte expectativa gerada pelos pais com relação ao desempenho esportivo das crianças, propiciam o aumento desse stress. No treinamento esportivo, a obsessão pela medalha parece engendrar um processo de compensação, pelas medalhas que os próprios pais não tiveram, mas se realizam se os filhos vierem a possuir.

O ritmo exagerado nos treinamentos a que as crianças são submetidas, na busca da vitória, em especial quando as mesmas são aprovadas num processo de seleção esportiva, ou disputam um lugar no time titular. Essa competitividade parece expor as crianças à tensões imensas, levando-as à depressāo e ansiedade (HART, 1992). E nessa prática, a inadequação das regras dos esportes oficiais para as crianças, sem observar melhor o seu nível de maturaçāo, suas possibilidades de execução, sua faixa etária, nível de crescimento, peculiaridades e interesses, parece que tem sido preponderante.

O desconhecimento por parte dos treinadores, orientadores ou professores, dos fatores que influenciam o crescimento e desenvolvimento da criança: fatores hereditários, ambientais, alimentação, sócio-econômícos, fatores psicossociais, parece sugerir que as vezes o grande problema no esporte das crianças... é o adulto! Percebe-se uma certa carência de profissionais especializados no setor infantil, ou estudiosos com maior competência para atuar nessa área. Com certeza, a inexistência da prática de Educação Física Escolar de $1^{\text {a }}$ a $4^{\text {a }}$ série no ensino público, orientada por profissionais de Educação Física, num periodo em que o desenvolvimento de habilidades motoras e movimentos básicos fundamentais se manifestam, tem contribuldo para o estado em que se encontra essa atividade entre as crianças. $E$ por vezes, o empecilho maior é a própria falta de tempo e espaço físico adequado para brincar. Criança não é adulto em miniatura, e brincar ainda é considerado hoje por grandes estudiosos da criança, a atividade mais séria e prazeirosa da infância (MESQUITA, 1985).

\section{PROVÁVEIS CONSEQŨÊNCIAS DA PRÁTICA ESPORTIVA INADEQUADA EM IDADE PRECOCE}

A sobrecarga emocional como conseqüência da cobrança que os pais, professores ou treinadores fazem em relação a performance positiva de resultado, tem sido fonte de stress para a criança (SMOLL et al., 1988). Como conseqüência, esse stress leva ao aparecimento de sintomas propícios à doenças ligadas ao ritmo de vida "moderno": colites, úlceras de estômago, enxaquecas, asma, em função de emoções abaladas. Por vezes, atrofia de membros menos exigidos ou crescimento desproporcional de outros, propiciando o aparecimento de desvios n-sturais. Mesmo o aparecimento de rachaduras e/ou uras ósseas espontâneas, sem uma explicação plausí- 


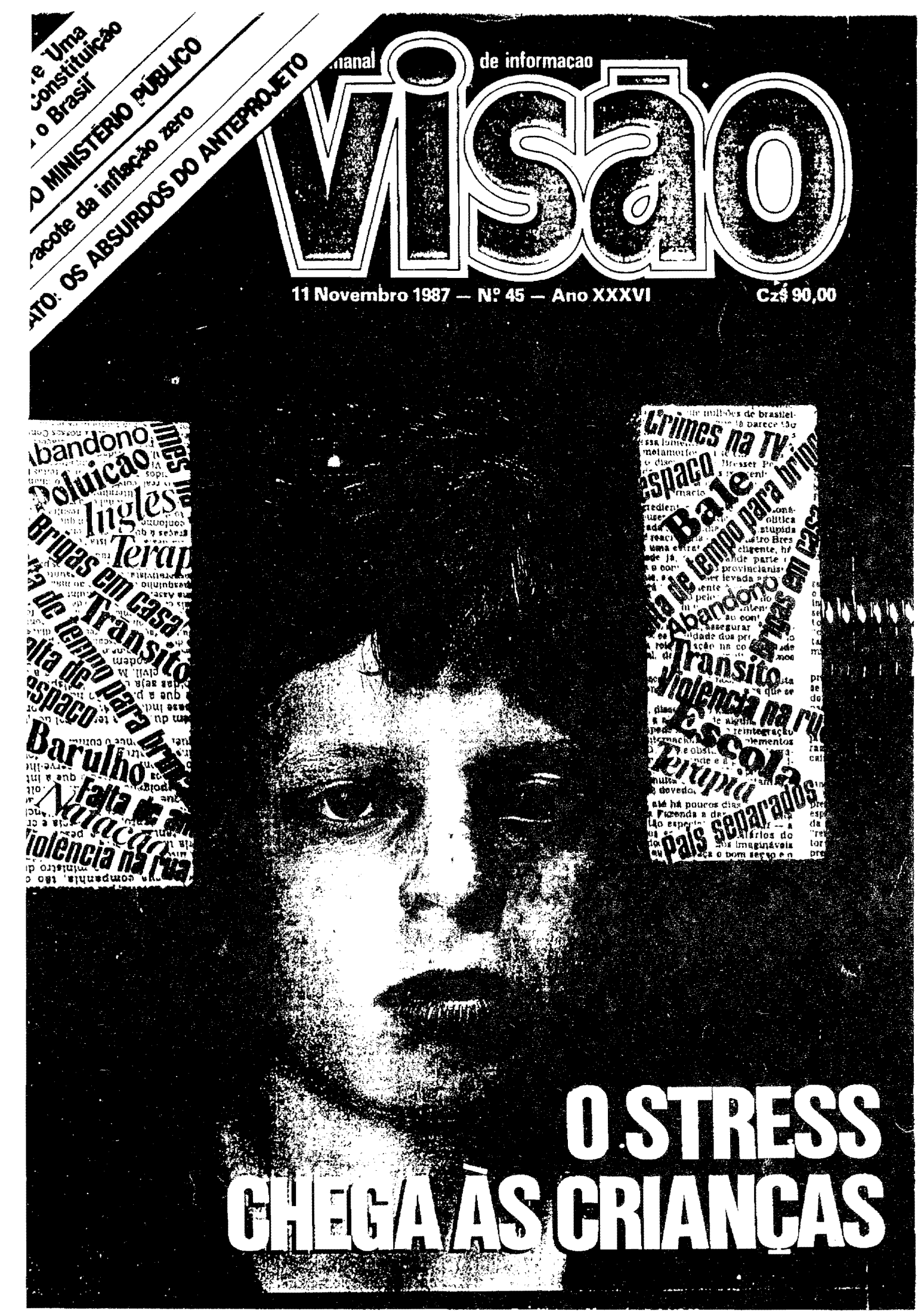

Figura 2 - O STRESS CHEGA AS CRIANÇAS 
vel podem acontecer durante esse processo. Alguns trabalhos cientificos nos Estados Unidos, tem citado a calcificação precoce das epifises ósseas, que pode limitar o crescimento normal da criança. Porém, acredita-se que a sindrome da saturação esportiva precoce, onde a criança no ápice do seu rendimento esportivo, passa a sentir aversão por horários rigidos de treinamento, ou da modalidade praticada pode contribuir para mantê-la afastada da atividade física no seu periodo de vida adulta. As crianças, pulverizadas entre dezenas de atividades, aperfeiçoam-se antes do perlodo crítico adequado para o desenvolvimento de suas habilidades, e não encontram tempo sequer para formar uma turma de amigos, talvez o que elas mais precisariam visando ampliar ou passar a ter o seu círculo social.

A limitação do potencial físico compativel com o desenvolvimento da musculatura cardíaca para a realização de esforços anaeróbicos parece sugerir a hipertrofia das paredes do coração, com consequente débito de oxigênio durante o trabalho muscular. $E$ quando os gestos técnico-esportivos são ensinados, um programa motor incorreto pode ser estabelecido e arquivado definitivamente ao se tentar ensinar habilidades motoras complexas às crianças, em especial no periodo em que o seu processo de maturação ainda se encontra em desenvolvimento.

Torna-se portanto cada vez mais necessário identi- ficar as necessidades da criança, e reavaliar constantemente suas fases de maturação, no sentido de propiciar atividades adequadas ao seu nível. Ter um cuidado maior visando encontrar um ponto de equilibrio entre os interesses dos adultos, e as necessidades de movimento da criança (Figura 3).

\section{CONCLUSŌES}

Grandes cuidados e cautela se fazem necessários aos profissionais envolvidos no processo de iniciação esportiva precoce da criança. Torna-se fundamental o domínio de conhecimentos especificos para atuar nesse setor, em especial a respeito de crescimento e desenvolvimento, aprendizagem motora, e psicologia da criança, caracterizando as idades aproximadas de desenvolvimento e os estágios em que a motricidade da criança se diferencia. Com certeza, a fisiologia, biomecânica e anatomia, bem como metodologias mais significativas para elaborar os programas de iniciação esportiva para diferentes idades se tornam pré-requisitos a esse profissional. Uma análise mais apurada dos fatores que influenciam no desempenho físico e na performance da criança, em especial com relação à habilidade esportiva que está sendo ensinada, vislumbrando os seus períodos ótimos de aquisição de habilidades motoras gerais, caracterizan-

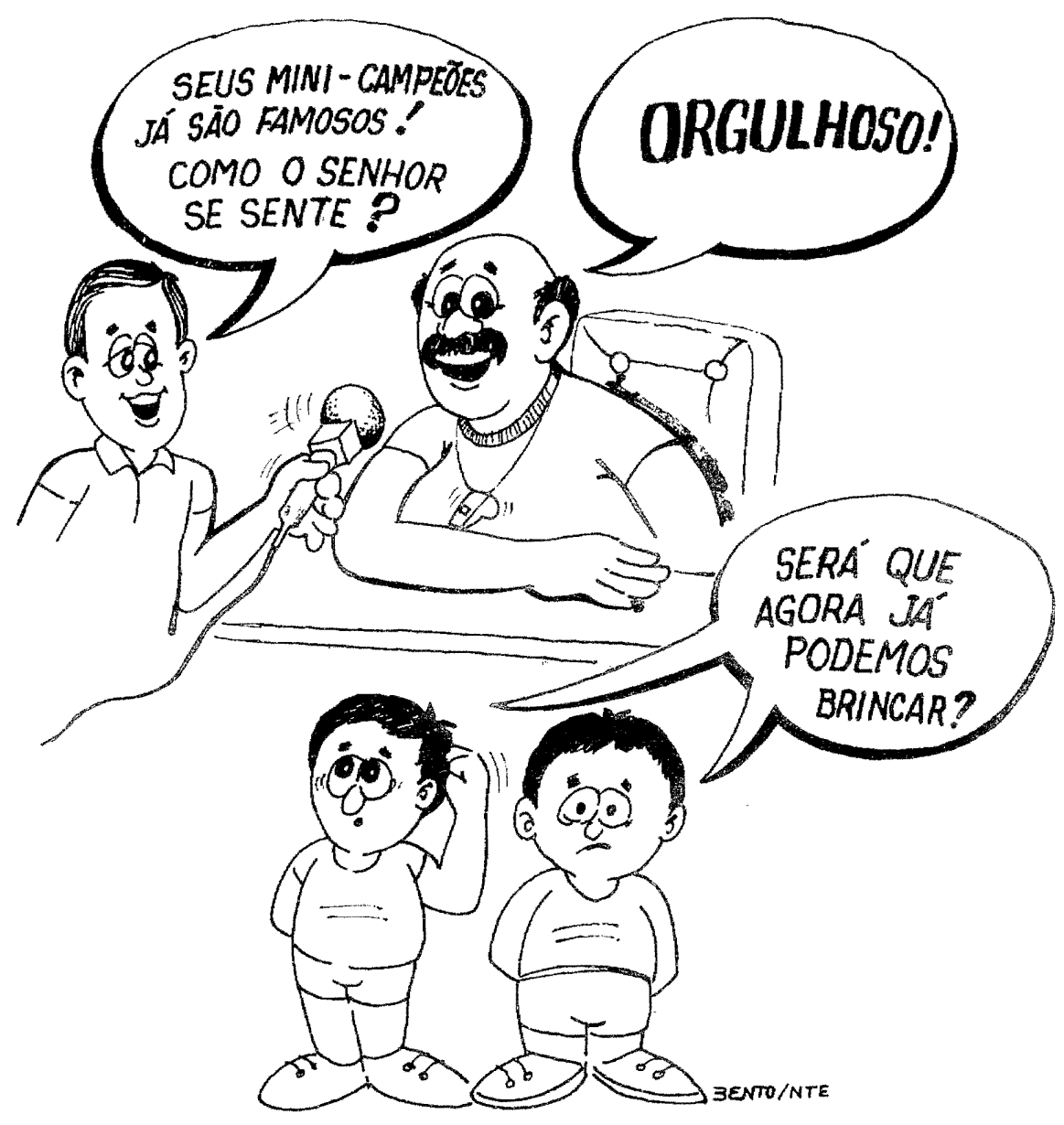

Figura 3 - UM CONFLITO ENTRE INTERESSES E NECESSIDADES

Semina Ci. Soc. $/$ Hum., v. $_{*} 15$, n. 3, p. 308-315 
do a idade mais propicia para o desenvolvimento das habilidades motoras especfficas, e as esportivas ou culturalmente aprendidas.

Se deveria atentar para as diferenças individuais nas diferentes etapas de crescimento e desenvolvimento motor, disseminando esses conhecimentos para serem aprendidos, estudados e debatidos com as crianças, e em especial com os seus pais. Os estudos sugerem que a época para inf́cio da atividade fĺsica competitiva não seja antecipada, e que a preocupação maior esteja voltada para a formação integral da criança, num ambiente em que prevaleça a liberdade de movimentos, a espontaneidade e a participação ativa. Para que essa participação se dê de forma significativa para a criança, ela deve causar alegria e prazer, estimulando seu auto-conhecimento e levando-a à interação com o mundo que a rodeia ${ }_{8}$ de maneira dinâmica, livre e criativa.

\section{SUGESTÕES}

Em função do presente estudo, sugere-se a democratização da prática esportiva, através de ações governamentais que busquem envolver um número maior de crianças na prática da atividade física com adequada orientação. $\mathrm{O}$ autoritarismo precisa ser eliminado de nossas aulas de Educação Fîsica, já que o mesmo propicia a formação de indivíduos passivos, sem opinião prốpria, e portanto passíveis de dominação. $A$ ațvidade fisica necessita ser estimulada sem obrigatoriedade. A partir do momento em que essa prática é obrigatória, ela se torna dispensável, nociva e condenável. E nessa prática, a diversificação da atividade precisa ser levada em conta, propiciando à criança oportunidades para constatar seus limites, qualidades e deficiências.

Sugere-se estimular a psicomotricidade da criança, levando-a ao seu auto-conhecimento e à valorização de si mesma, bem como sua interação com outras crianças e com o mundo que a rodeia. $O$ seu desenvolvimento integral deve ser buscado sempre. A formaçäo de grupos homogêneos na prática esportiva competitiva precisa levar em conta o nível maturacional da criança, não apenas a sua idade cronológica. Torna-se necessário que o profissional saiba identificar as diferenças existentes quanto à idade cronológica, biológica, neurológica, mental, anatômica, sexual e dental.

Recomenda-se o desenvolvimento de te̊cnicas e estratégias para adequar a prática da atividade físico-esportiva ao nlvel de interesse, necessidades e possibilida. des de execução da criança, motivando a prática perma. nente para o resto de sua vida, e propiciando saúde. Tanto os pais quanto as crianças necessitam ser informa. dos dos riscos de lesões nas atividades esportivas, e em especial como prevení-los, mas ao mesmo tempo ofere. cer condições para que as crianças decidam como participar dessas atividades.

Espera-se que não seja valorizado demais o grande desempenho, ao menos a nivel escolar, não forçando $e x$. cessivamente as crianças na prática competitiva. A escola exige não apenas para formar campeões, mas os futuros indivíduos adultos. Movimento \& vida, logo a prática da atividade fisica deve causar efeitos de alegria e prazer.

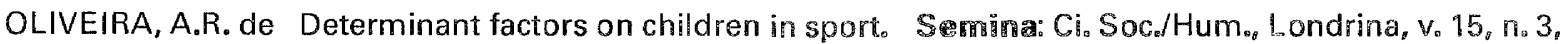
p. 308-315, Sept. 1994.

ABSTRACT: This study has the purpose of analyzing the possible factors that early sport practice can develop on childsen, especially without pedagogical and scientific base. The lack of a specific subject concentrated on child development siudies in most physical education courses in Parana State, according to Sports and Tourism Secretary, presents different degrees of competency levels in the field. The more meaningful the Physical Education teaching is the greater the respect to the principles of age, growth, maturation and development. It is necessary to improve sport skills, and to respect children's individual differences. The child leams when he/she is ready to learm, and excessive emphasis on winning should be avoided before the age of twelve, especially for injuries prevention. The awareness of child development changes and the modification of the curriculum in the Physical Education Schools are suggested. Physical activities for children should be meaningful, according to children age level and motivation, stimulating an active and healty lifestyle.

\section{KEY-WORDS: Child; early sport practice; determinant factors}

\section{REFERENCIAS BIBLIOGRÁFICAS}

ALVES, R. Conversas com quem gosta de ensinar. São Paulo: Cortez, 1985. 20p.

ARA ÚJO, C.G.S. Crescimento, Desenvolvimento e Aprendizagem Motora. Unidade II - Ensino à Distância. Brasflia: Ministério da Educação, 1987. p. 5-16.

Semina Ci. Soc./Hum., v. 15, n. 3, p. 308-315
HART, A.D. Stress and your child. Dallas: Word Publishing, 1992. p. 33-90.

HURTADO, J.G.G.M. Educação Flsica Pré-Escolar e Escolar de 1' a $4^{a}$ série. Porto Alegre: Prodil, 1987. p. 18-56. 
MALINA, R.M.; BUCHARD, C. Growth, Maturation and Physical Activity. Champaign: Human Kinetics Publishers, Inc. 1991. p. 443-465.

MESQUITA, R.P. Educação Física nas Escolas Brasileiras Uma realidade que ainda amedronta. Revista Sprint, Rio de Janeiro, Ano 4, vol. 3, p. 52-56, mar./abr. 1985.

PINI, M.C. Fisiologia Esportiva. Rio de Janeiro: Guanabara Koogan, 1978. p. 221-232.
SMOL, F.L.; MAGILL, R.A.; ASH, M.J. Children in Sport. Champaign: Human Kinetics Publishers, Inc., 1988. p. 43-67.

TUBINO, J.M.G. Metodologia Cientfica do Treinamento Desportivo. São Paulo: Instituição Brasileira de Difusão Cultural, 1979. p. 420-423.

WEINECK, J. Manual de Treinamento Esportivo. 2. ed. Rio de Janeiro: Manole, 1986. p. 31-45.

Recebido para publicação em 01/4/1991

CUNHA, M.I. da O bom professor e sua prática. Campinas: Papirus, 1989.

Elaborada por: SILZA MARIA PAZELLO VALENTE ${ }^{1}$

O que motivou a autora a abordar o tema foi sua experiência, como professora, em situações diversas: professora de Didática, na Universidade Federal de Pelotas, docente de Metodologia do Ensino em Cursos da Faculdade de Educação e Apoio Pedagógico junto a professores em serviço nos $2^{\circ}$ e $3^{\circ}$ graus.

Cunha valoriza a sala de aula como lugar privilegia* do do ato pedagógico escolar (daí porque se volta para ela ao procurar caracterizar e compreender a educação institucionalizada), mas a coloca num todo maior, a escola, e esta na sociedade. Procura, portanto, colocar o micro (sala de aula) em um universo cada vez mais amplo que forneça elementos para compreendê-la.

Justifica a escolha do professor como foco de pesquisa, näo como uma maneira de valorizá-lo acima dos outros elementos que compõem o universo escolar, mas pelo seu interesse pessoal na compreensão do desempe. nho do mesmo.

Para chegar à compreensão do papel do professor na realidade âtual ${ }_{z}$ fez um levantamento histórico da edu. cação desde suas origens com os jesuitas ${ }_{e}$ passando pela 1a Republica (foremente infuenciada pelo liberalismoli pelos anos 30, com a introduça das ideias escolanovistas momento onde aponta o verdadeiro papel que a Escola Nova desempenhou como mantenedora do modelo burguês de sociedade. Recuperou a fase dos anos 60 , parte da decada de 70 , fortemente influenciada pelo tecnicismo e penetrou em um panorama cheio de contradi çöes e desesperanças fruto falido de um passado repleto de tentativas mal sucedidas. $A$ educaço dos anos 80 pretendia ser critica e questionadora, colocava o politico no centro das discussōes, mostrava que o problema da educação é estrutural, mas continuou tendo no professor um reprodutor; só que agora um reprodutor dono de um discurso que critica, questiona e se pretende revolucionário.

A revisão bibliográfica adentrou também o terreno das pesquisas sobre o professor e detectou que a maior parte delas "sāo estudos-preditivos sobre as qualidades e habilidades necessárias ao profissional de ensino".

Segundo a autora, as pesquisas norte-americanas foram as mais divulgadas em nosso país. Os cursos de pós-graduação que foram implantados após a Reforma Universitária de 1968, seguiram na mesma esteira e também a produção brasileira foi marcada pela linha positi vista. Só mais recentemente é que a produção da área educacional incluiu o polftico nas suas anålises e possibilitou um grande avanço na compreensäo do fenômeno educativo intra-escolar. Aponta, ainda, na revisão bibliografica ${ }$ um "esforco bastante grande dos intelecvais

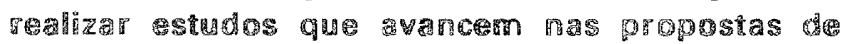

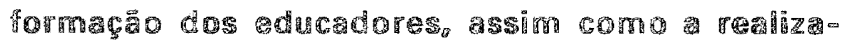

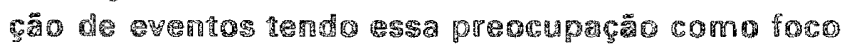
centrat

Cunha se posiciona favoravel ao professor que faz da sala de aula uma fonte permanente de pesquisa en: $^{-}$ tendendo que so assim s posshel a ele analisar e criticar

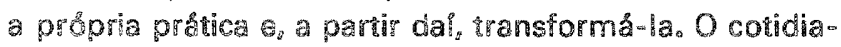

1 - Departamento de Educação, Centro de Educaçäo, Comunicação e Artes, Universidade Estadual de Londrina, Caixa Postal 6001, Londrina, Paraná, Brasill, CEP 86051-970. 